\title{
Thermal and toughness property studies on a polybenzimidazole-modified epoxy resin system
}

\author{
Kandasamy Natarajan, ${ }^{1 *}$ Rao Prakash Kumar, ${ }^{2}$ PV Reddy, ${ }^{3}$ NM Nanje Gowda ${ }^{4}$ and \\ RMVGK Rao ${ }^{5}$ \\ ${ }^{1}$ Department of Chemistry, RV College of Engineering, Bangalore, India \\ ${ }^{2}$ Department of Chemistry. Sri Jagadguru Renukacharya College, Bangalore, India \\ ${ }^{3}$ Central Power Research Institute, Bangalore, India \\ ${ }^{4}$ Department of Chemistry, Bangalore University, Bangalore, India \\ ${ }^{5}$ FRP Pilot Plant, National Aerospace Laboratories, Bangalore, India
}

\begin{abstract}
The effect of polybenzimidazole (PBI) on a silica-filled epoxy resin matrix has been investigated. Polybenzimidazole (PBI) was incorporated into a difunctional epoxy resin matrix to the extent of $10 \%$, before being cured with an anhydride hardener. The effects of PBI on the curing reaction and glass transition temperature $\left(T_{k}\right)$ and on the toughness of the cured epoxy matrix have been studied using diflerential scanning calorimetry (DSC), thermogravimetric analysis (TGA) and a universal testing machine (Instron). The results indicate that the PBI modifier enhanced not only the glass transition temperature of the difunctional epoxy matrix but also its toughness, by its catalytic action. Further investigations have been carried out on the fractured specimens, using scanning electron microscopy (SEM) to support the enhanced toughness property of the epoxy matrix.

(9) 2000 Society of Chemical Industry
\end{abstract}

Keywords: polybenzimidazole; difunctional epoxy; anhydride hardener; catalytic; glass transition; toughness; SEM

\section{INTRODUCTION}

Among thermosetting resins, epoxy resins exhibit outstanding adhesive properties towards a wide variety of fillers, substrates and reinforcing agents, very low shrinkage during curing, chemical resistance, and electrical insulation. Because of these properties they find extensive applications in both the electrical industry and in structural composites. Even though epoxy resins exhibit several advantageous properties, they are inherently brittle due to the high crosslink density developed in the cured state. ${ }^{1}$ Bucknall et al. ${ }^{2}$ reported various techniques for enhancing the toughness of epoxy resin matrices. It was observed that toughness enhancement techniques resulted in loss of glass transition temperature of the cured epoxy matrix, ${ }^{3}$ but later it was proved that with suitable choice of modifiers and curing agents, the toughness of the epoxy matrix can be enhanced without sacrificing the glass transition temperature. ${ }^{4}$ Anhydride curing agents are well known for their production of high glass transition temperature epoxy matrices. ${ }^{5}$ Furthermore, a polybenzimidazole thermoplastic polymer has been reported as a high $T_{\mathrm{g}}$ polymer ${ }^{6}$ and as a catalyst, ${ }^{7}$ for curing epoxies.

In the present paper, investigations were carried out by using high $T_{\mathrm{g}}$ polybenzimidazole as a catalytic agent to accelerate the curing reaction of a difunctional epoxy in the presence of an anhydride hardener. The castings obtained were studied for glass transition temperature using differential scanning calorimetry (DSC), thermal stability by thermogravimetric analysis (TGA) and toughness properties by an Instron universal testing machine.

\section{EXPERIMENTAL}

\section{Materials}

Materials used were a difunctional epoxy resin, namely the diglycidyl ether of bisphenol-A (DGEBA) coded CY-205 from Ciba Geigy Ltd, an anhydride curing agent coded HY 905 (ricacid (5-methyl phthalic anhydride) from Ciba Geigy Ltd, and polybenzimidazole (poly [2,2'-(diphenyl) 5,5'-di(benzimidazole)] (PBI), a catalytic modifier synthesized in-house, and a silica filler.

\section{Preparation of blends}

Finely-ground polybenzimidazole particles $(10 \%$ by weight) were added to the epoxy resin, followed by the addition of silica filler (40\%). A stoichiometric quantity of curing agent was added while stirring well. The resultant blend was poured into an aluminium mould and heated to $150^{\circ} \mathrm{C}$ for $3 \mathrm{~h}$; this was followed by post curing at $180^{\circ} \mathrm{C}$ for $30 \mathrm{~min}$ and at $210^{\circ} \mathrm{C}$ for

- Correspondence to: Kandasamy Natarajan, Department of Chemistry, AV College of Engineering, Bangalore, India

(Feceived 18 January 2000; revised version received 20 March 2000; accepted 24 March 2000) 


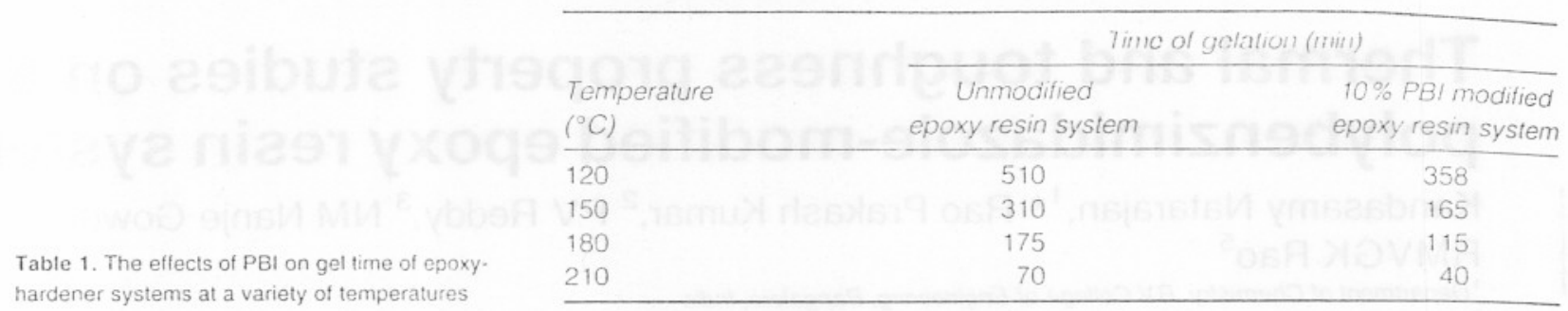

$30 \mathrm{~min}$. The specimens obtained were used for various tests.

\section{Determination of gelation time}

The effect of PBI on gelation time of the epoxyanhydride system, at a variety of temperatures was studied by the cup plate gel time (ASTM 242) method. After mixing the resin, hardener, filler and catalyst, the surface of the reaction mixture was probed with a needle, and the time required for the reaction mixture to become non-adherent to the needle was recorded. The values obtained are presented in Table 1.

\section{Thermal characterization}

DSC

The glass transition temperature of the cured sample (7.00 mg) was-studied-using-a differential-scanning calorimeter (DSC-2910, TA Instruments), under a nitrogen atmosphere at a flow rate of about $60 \mathrm{mlmin}^{-1}$. To record a stabilized glass transition temperature $\left(T_{\mathrm{g}}\right)$, the samples were preheated in the calorimeter and then scanned over the temperature range $30-350^{\circ} \mathrm{C}$ at a heating rate of $10 \mathrm{~K} \mathrm{~min}^{-1}$. The obtained data are reported in Fig 1.

\section{$T G A$}

The thermal stability of pure PBI, cured-PBI incorporated epoxy and unmodified epoxy-anhydride samples (sample size about $7.20 \mathrm{mg}$ ) were studied using a thermogravimetric analyser (TGA-model-951, Dupont 1090). Tests were run at a heating rate of $10 \mathrm{~K} \mathrm{~min}^{-1}$ under nitrogen atmosphere at a flow rate of about $60 \mathrm{ml} \mathrm{min}^{-1}$. The thermograms are shown in Fig 2.

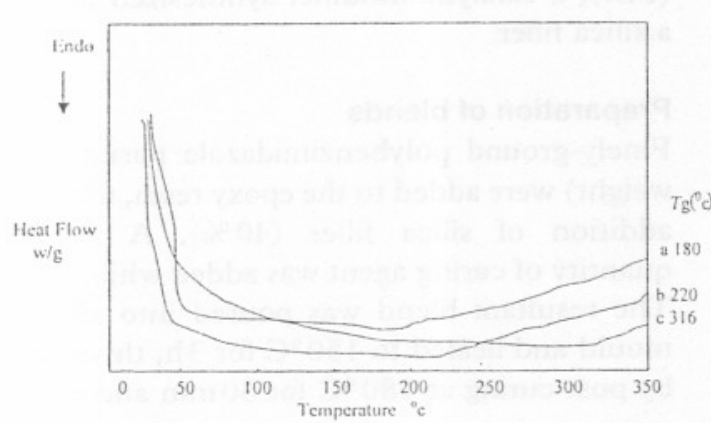

Figure 1. DSC thermograms of cured resin systems: curve a, unmodified epoxy-hardener $\left(T_{g} 180^{\circ} \mathrm{C}\right)$; curve $\mathrm{b}, \mathrm{PBI}$ modified epoxy-hardener matrix $\left(T_{g} 220^{\circ} \mathrm{C}\right)$; curve C, PBI $\left(T_{g} 316^{\circ} \mathrm{C}\right)$.
Determination of toughness properties

The plane-strain fracture toughness $\left(K_{\mathrm{IC}}\right)$ of the cured unmodified and of PBI-modified epoxy resin samples were determined as per the ASTM-E-399-74 test method. Three-point bend specimen samples were prepared by machining a central ' $V$ ' notch of $3 \mathrm{~mm}$ depth on one edge of the sample followed by a sharp notch of $0.2 \mathrm{~mm}$ using a razor blade. The specimens were loaded in three-point bending configuration with a span length of $40 \mathrm{~mm}$ in a Universal testing machine (Instron model 6025) at a cross-head speed of $1 \mathrm{mmmin}^{-1}$ at $23^{\circ} \mathrm{C}$ and $55 \%$ relative humidity. Six specimens were tested in each case and the average $K_{\mathrm{IC}}$ values obtained are reported.

Fractographic studies

The obtained fractured specimens were used for fractographic analysis. The fractured areas of the specimens were coated with a gold/palladium alloy by vapour deposition and examined with a scanning electron microscope (SEM) (Jeol JSM-840-A) at about $6.0 \mathrm{kV}$. The micrographs are presented in figs 3 and 4 .

\section{RESULTS AND DISCUSSION}

The results presented in Table 1 indicate that the gel time of curing reaction between epoxy resin and anhydride hardener was accelerated by the PBI modifier. This indicates that $10 \%$ addition of PBI accelerated the reaction and reduced the gel time to about half that of the unmodified system, at a variety of temperatures.

The DSC thermograms exhibited in Fig 1 clearly

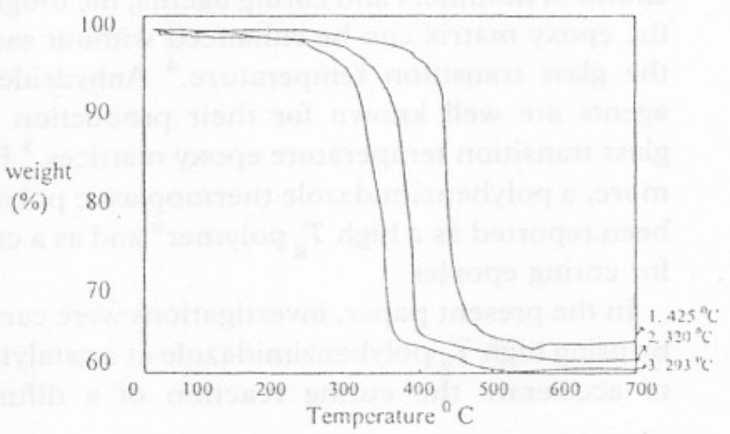

Figure 2. TGA thermograms of pure PBI (curve 1), cured PBI modificd epoxy resin system (curve 2) and unmodified epoxy-anhydride system (curve 3). 


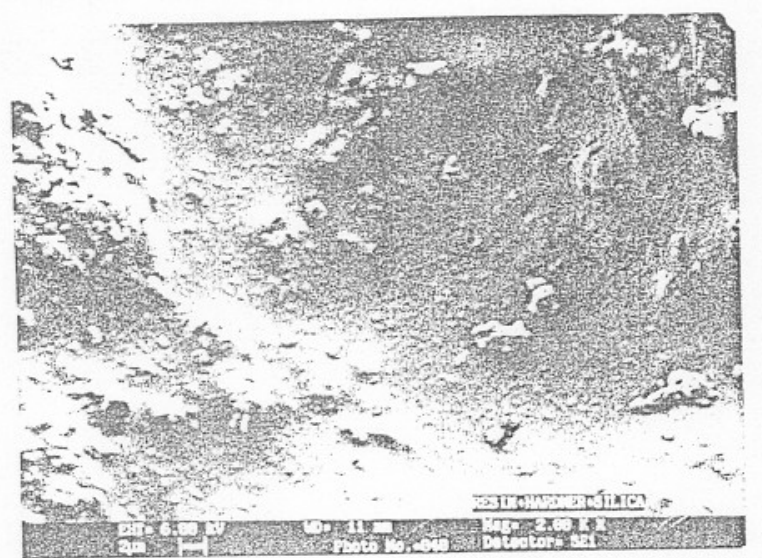

Figure 3. Scanning electron micrograph of the fractured surface of the unmodified epoxy resin system.

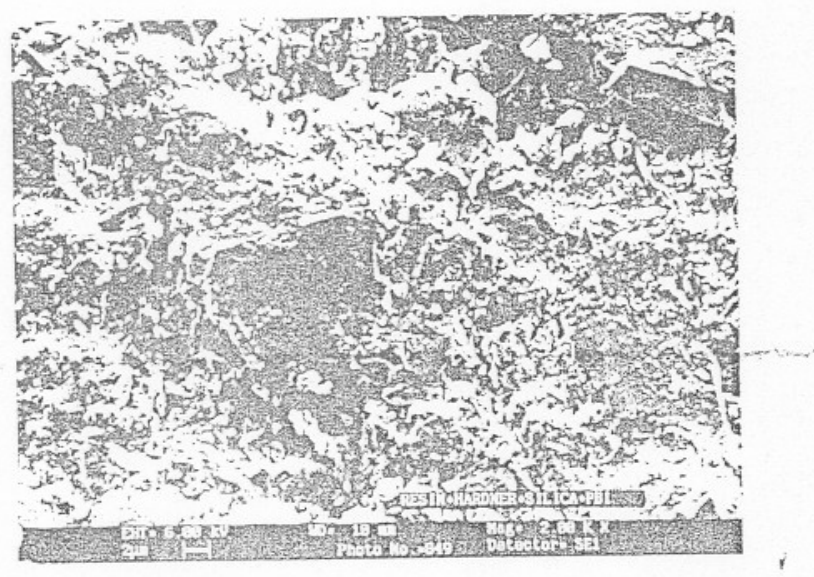

Figure 4. Scanning electron micrograph of the fractured surface of the PBImodified epoxy resin system.

indicate that the glass transition temperature $\left(T_{\mathrm{g}}\right)$ of the unmodified cured epoxy resin-hardener matrix is $180^{\circ} \mathrm{C}$, of the PBI modified epoxy resin-hardener matrix is $220^{\circ} \mathrm{C}$ and of pure PBI is $316^{\circ} \mathrm{C}$. It is evident that the PBI raises the glass transition temperature of the epoxy resin-hardener matrix system from $180^{\circ} \mathrm{C}$ to $220^{\circ} \mathrm{C}$

Furthermore, the TGA thermograms exhibited in Fig 2 indicate that the onset temperature of decomposition or degradation of PBI, PBI modified epoxyhardener and unmodified epoxy-hardener system, is $425^{\circ} \mathrm{C}, 320^{\circ} \mathrm{C}$, and $293^{\circ} \mathrm{C}$, respectively, at $5 \%$ weight loss. Fracture toughness values $\left(K_{1 C}\right)$ of the PBI modified resin system show enhancement in the $K_{\mathrm{IC}}$ value from 0.59 to $0.83 \mathrm{MPam}^{1 / 2}$.

The enhancement in the toughness value for the PBI modified epoxy resin system was supported by fractographic analysis. The scanning electron micrographs exhibited in ligs 3 and 4 indicate that more rough surface was developed by PBI in the epoxy matrix (Fig 4) than in the unmodified resin system (Fig 3). It is a well known fact ${ }^{6}$ that the rougher the surface the higher will be the energy absorption. Hence, more energy was absorbed by PBI-modified resin systems.

\section{CONCLUSIONS}

Polybenzimidazole not only accelerated the curing reaction between the difunctional epoxy resin and anhydride hardener (CY-205 and HY-905), but also increased the glass transition temperature $\left(T_{\mathrm{g}}\right)$ of the matrix up to $220^{\circ} \mathrm{C}$, when $10 \%$ was added. It also considerably enhanced the toughness of the epoxy matrix.

\section{ACKNOWLEDGEMENTS}

We gratefully acknowledge the support obtained from the RV College of Engineering, National Aerospace Laboratories, Central Power Research Institute, and Bangalore University, Bangalore.

\section{REFERENCES}

1 Riew CK, Rowe EH and Sicbert AR, Toughness and brituleness of plastics, in ACS Advances in Chemistry Series No. 154, Ed by Deanin RD and Cignol AM, American Chemical Society, Washington DC (1976).

2 Bucknall CB, Patridge IK, Jayle L, Nozue I, Fernyhough A and Hay JN, Polym Prepr 33(1):378 (1992).

3 Horiuchi S, Street AC, Ougizawa T and Kitano T, Polymer 35:5283 (1994).

4 Natarajan K and Rao RMVGK, High Performance Polym 6:241248 (1994).

5 Penn S and Chiao TT, Epoxy resins, in Handbook of Epoxy Resins, l:d by Lee $H$ and Neville K, MeGraw Hlill, New York. p 69) (1967).

6 Natarajan K and Rao RMVGK, Polymer processing rowads AD) 2000, Proceedings of the Polymer Processing Socicty's Asia/ Australia regional meeting held at Singapore p 231 (1996).

7 Woo EM and Seferis JC, f Appl Polym Sci 40:1237 (1990). 